\title{
HISTORIA CONCEPTUAL Y FILOSOFÍA DE LA HISTORIA DESDE UNA PERSPECTIVA LEIBNIZIANA ${ }^{1}$
}

\section{CONCEPTUAL HISTORY AND PHILOSOPHY OF HISTORY FROM A LEIBNIZIAN PERSPECTIVE}

\author{
CONCHA ROLDÁN \\ Instituto de Filosofía, CSIC
}

A Quintín Racionero, más allá del tiempo y del espacio, en amistad.

Resumen: El presente trabajo pretende entablar un diálogo crítico entre la historia conceptual y la filosofía de la historia. Por una parte, en lo tocante al supuesto inicio de la "identidad semántica" de la modernidad; por otra, en la propia noción de "saber histórico" y con ella las experiencias históricas colectivas e individuales que lo conforman: no podemos olvidar que el sujeto del saber histórico no es sólo -o fundamentalmente- el

\footnotetext{
${ }^{1}$ Este artículo se ha realizado en el marco de los proyectos de investigación "Prismas filosófico-morales de las crisis. Hacia una nueva pedagogía sociopolítica" (PRISMAS: FFI201342935-P), "Leibniz en español- 3" (FFI2014-52089-P) y "Philosophy of History and Globalisation of Knowledge. Cultural Bridges Between Europe and Latin America" (WORLDBRIDGES: F7-PEOPLE-2013-IRSES: PIRSES-GA-2013-612644).
} 
estudioso de la historia, sino también quienes "hacen" esa historia o la "padecen" y que también contribuyen a gestar el humus conceptual de una experiencia que se traduce -o debería traducirse- en responsabilidad ética por esos mismos conceptos. La crítica a la filosofía clásica de la historia tiende así la mano a la propuesta de la rehabilitación de una filosofía crítica de la historia, aspectos ambos en los que se presentan como antecedentes diferentes conceptos leibnizianos, como no podía ser de otra manera en un trabajo dedicado a mi querido y extrañado amigo Quintín Racionero -que ya no será lo mismo sin poder discutirlo con él².

Palabras Clave: Filosofía de la historia, historia conceptual, saber histórico, modernidad, filosofía crítica, Leibniz.

AвSTRACT: The present text aims to establish a critical dialogue between Conceptual History and the Philosophy of History. On one hand, this dialogue refers to the purported beginning of "semantic identity" in Modernity. On the other hand, it refers to the very notion of "historical knowledge" and with it, of the collective and particular historical experiences of which it is made: we cannot forget that the subject of historical knowledge is not merely -or fundamentally- the History scholar, but those who "make" that History or "suffer" it, as well. Moreover, they also, in fact, contribute to create the conceptual humus of an experience that is translated -or should be translated- to ethical responsibility regarding these very concepts. The critique of Classical Philosophy of History thus reaches out to the proposal to rehabilitate a Critical Philosophy of History; in both of these aspects of the general discipline, different Leibnizian concepts are presented as antecedents. This could not be otherwise in a text devoted to my beloved and long-missed friend Quintín Racionero -a text that will never be the same because I can no longer discuss it with him.

\footnotetext{
${ }^{2}$ No quería dejar de participar en este monográfico de la revista Éndoxa, dedicado a la memoria de Quintín Racionero, pero se me ha hecho muy cuesta arriba escribir estas líneas que carecen de la festividad de un regalo de cumpleaños. Tu reloj se paró hace ya cuatro años y me parecía antinatural escribir para ti un trabajo bajo la dura certeza de la imposibilidad de discutir contigo su contenido... jcontrovertidamente!, como a ti te gustaba hacer, sacando punta a las cosas y enfrentándonos al fin y a la postre con muchas más aristas del problema de las que nosotros inicialmente presentábamos. ¡Qué bonito habría sido agasajarte por tu 65 cumpleańos en 2013! Lamentablemente no podemos jugar a los contrafácticos, pero tampoco queremos dejar de recordar a quienes han ocupado un puesto de referencia en nuestras vidas y ya no están. Te dedico, pues, unas reflexiones entre Leibniz y la filosofía de la historia, que fueron acaso algunos de nuestros temas comunes más recurrentes, mientras te veo esbozar una sonrisa por detrás de tu dedicatoria en La inquietud en el barro: "Es bonito sentir cómo la amistad se sobrepone a las interrupciones del tiempo”. ¡Ojalá se trate sólo de una interrupción! Que tenemos que hablar de muchas cosas compañero del alma, compañero...
} 
KeYwords: Philosophy of history, conceptual history, historical wisdom, modernity, critical philosophy, Leibniz.

\section{Preámbulo. ¿Otro probable inicio para la historia conceptual?}

Hace unos años escribí un artículo en homenaje al autor de la historia conceptual, donde mi intención era relacionar "Ilustración" y "Semántica histórica", por una parte, para criticar "la estricta circunscripción que (Koselleck) hace del nacimiento de esa modernidad ilegítima"', por otra, para poner de manifiesto el protagonismo de Leibniz en los orígenes de la modernidad europea, refiriéndome al Leibniz original y no al tamizado por Wolff y la denominada "escuela leibnizo-wolffiana". Aunque en aquel trabajo anticipaba ya algunos de los conceptos leibnizianos a que aquí me referiré, mi intención allí era establecer un diálogo entre la denominada Ilustración y la Historia Conceptual; ahora quisiera poner en relación la "semántica histórica" de la historia conceptual con la "filosofía clásica de la historia", en un intento por rehabilitar en nuestros días "una filosofía crítica de la historia"”.

Aunque Koselleck fue precisando a lo largo de los años el origen otorgado inicialmente a la historia conceptual en el arco temporal que iba de 1750 a 1850 (Sattelzeit), y en la que a su entender se perfilarían nuestras señas de identidad semántica, siempre se mantuvo en fechas muy próximas a su "encabalgamiento de la modernidad", con lo que no creo que hubiera aceptado este otro

\footnotetext{
3 "Ilustración y semántica histórica: el protagonismo de Leibniz", en Teorías y prácticas de la Historia Conceptual, Faustino Oncina (ed.), CSIC-Plaza y Valdés, Madrid, 2009, p. 398. En el mismo volumen colectivo José Luis Villacañas ("Acerca del uso apocalíptico de la E. Media", op. cit. p. 97) insiste en otro sentido en que "la teoría de la secularización se convierte así para Koselleck en una teoría sobre la ilegitimidad".

${ }^{4}$ A estos esfuerzos dediqué como investigadora principal la realización del proyecto de investigación "Filosofía de la historia y valores en la Europa del siglo XXI" (FFI2008-04279// FISO), en cuyo marco de investigación vieron la luz varias publicaciones al respecto, no sólo mías sino también de Roberto R. Aramayo o Johannes Rohbeck, así como en el proyecto internacional "Enlightenment and Global History" (ENGLOBE: Marie Curie Inicial Training Network: FP7-PEOPLE-2007-1-1-ITN, en cuyo marco publicamos el volumen colectivo New Perspectives in Global History (Edited by Daniel Brauer, Iwan D'Aprile, Günther Lottes, Concha Roldán), Wehrhahn Verlag, Hannover, 2012.
} 
"probable inicio" -por emplear terminología kantiana5- que yo propongo y que se remontaría casi un siglo hacia delante, a un pensador que sin embargo algunos autores han dado en calificar de perteneciente a la "primera ilustración" o "ilustración temprana" 6 , a saber, G.W. Leibniz, de cuya muerte este año se cumple el tricentenario. Un cambio de inicio que, por "probable", no quiere arrogarse determinismo alguno, sino reivindicar un mero espacio de contingencia en la historia de la filosofía, que sin embargo nos permita interpretar la filosofía clásica de la historia con una mayor precisión que el inicio más tardío preconizado por Reinhart Koselleck.

Si tuviéramos que definir aforísticamente en qué consiste la historia intelectual de la modernidad, podríamos afirmar que no es distinta de la historia de la formación del lenguaje moderno. Ahora bien, las dificultades comienzan a la hora de ponerse de acuerdo sobre este último que no es, en definitiva, sino una suma demasiado abigarrada de categorías, de tradiciones, de supuestos, de prejuicios, de conceptos y de metáforas como para atribuirle una identidad fuerte. Sin duda, el llamado "giro lingüístico" y la crítica posmoderna vinieron a animar esos debates en las últimas décadas del siglo $\mathrm{XX}$, haciendo que nos ocupáramos cada vez más de analizar y definir los "conceptos fundamentales" de nuestros haberes éticos y políticos, para dirimir qué contenido semántico conservan de su pasado y qué es lo que aportan de radicalmente nuevo en la construcción de nuestra racionalidad posmoderna, como restos o indicios de un lenguaje que siempre tenemos que volver a interpretar, bien desde la perspectiva de la continuidad, bien desde la discontinuidad. En eso consiste nuestra tarea como historiadores de las ideas, en descubrir los elementos pertinentes del pasado y en interpretar su efectividad en el panorama contemporáneo, pues si el pasado está abierto, nuestra herencia ya no está unívocamente determinada, sino que se nutre de un abanico de posibilidades capaces de cristalizar en diversas historias.

Desde la perspectiva de la historia conceptual (Begriffsgeschichte) ha sido usual querer definir las ideas clave de nuestro arsenal moral y político (la libertad, la autonomía, el progreso, la legitimidad, la soberanía, o la secularización) en

\footnotetext{
${ }^{5}$ Juego aquí con el título del famoso opúsculo de Kant Probable inicio de la historia humana (1786), que traduje junto con Roberto R. Aramayo en Ideas para una historia universal en clave cosmopolita y otros escritos de Filosofía de la Historia, Tecnos, Madrid, pp. 57-77.

${ }^{6}$ Cf. Max Wundt, Die deutsche Schulmetaphysik des 17. Jahrhunderts, Mohr, Tübingen 1939 y Die deutsche Schulphilosophie im Zeitalter der Aufklärung, Olms, Hildesheim, 1945, y entre nosotros Agustín Andreu, Ilustración e Ilustraciones, Universidad Politécnica de Valencia, 1997.
} 
virtud de un doble componente: de un lado, lo que tienen de radicalmente innovador -de exponente de una experiencia específicamente moderna-; de otro, lo que conservan, a la manera de un palimpsesto o pentimento, de modos de pensar y de ordenar el mundo distintos y anteriores a la emergencia del novum de la Modernidad. De manera que la genuina identidad moderna se capta -o así lo parece- cuando, sobre el confuso trasfondo de una multiplicidad de lenguajes y de tradiciones puede destacarse la chispa centelleante de lo inédito e innovador, cuando -con palabras de Koselleck- "un novedoso Erwartungshorizont u horizonte de expectativas se emancipa del Erfahrungsraum o espacio de experiencia habitual"7.

La mayor parte de nuestras categorías vendrían a ser entonces, de acuerdo con este planteamiento, lo que resultó de los distintos modos de zanjar la "disputa de los antiguos y modernos" (querelle des anciens et modernes) o, en el supuesto de que asistamos ahora a la emergencia de novedad, lo que ha resultado de la "disputa entre modernos y posmodernos". "De la crítica surge la filosofía de la historia. La crítica es el heraldo de la crisis" -escribió Koselleck en Critica $y$ crisis del mundo burgués ${ }^{8}$. Y en sus reflexiones posteriores Koselleck precisará que somos herencia de una cosmovisión moderna gestada en esa Sattelzeit, en la que a su entender se perfilarían nuestras señas de identidad semántica. No es mi intención entrar ahora en el espinoso tema de la periodización de la historia -o de la historia de la filosofía- sino sólo para llamar la atención sobre el problema que plantea esta fijación temporal que lleva a cabo la teoría de la historia conceptual en su emisión del diagnóstico de la modernidad, a saber, precisamente su insistencia en "una línea triunfante de la Ilustración", en nuestra posibilidad de reconstrucción e interpretación "objetiva" de la misma -al margen de nuestras ideologías, convicciones y experiencias presentes. Por eso, mi propuesta de situar un siglo antes los orígenes de los conceptos modernos $^{10}$, y darle a Leibniz en esta

\footnotetext{
${ }^{7}$ Cf. R. Koselleck, Vergangene Zukunft, Suhrkamp, 1989, sobre todo las pp. 349-375.

${ }^{8}$ Kritik und Krise, Suhrkamp, Freiburg/München, 1959, 6.

${ }^{9}$ Esta es la tesis que defendí en Entre Casandra y Clio en 1997, y que no me parece muy distante de la que Jonathan Israel ha defendido en su libro Radical Enlightenment: Philosophy and the Making of Modernity, 1650-1750, Oxford Universit Press 2001, sólo que el confiere un papel mucho más protagonista a Spinoza que a Leibniz para el desarrollo de los conceptos modernos (hay traducción castellana, La ilustraciñon radical, en FCE, 2012)

${ }^{10}$ En este sentido, simpatizo mucho más con la periodización que lleva a cabo Giuseppe Duso para la génesis de los principales conceptos modernos (entendiendo por aquellos los que se difunden socialmente y se convierten en sentido común" en el período de la Revolución Francesa), que acaecería en el contexto de las doctrinas iusnaturalistas y del contrato social, en tanto que origen de un nuevo modo de entender el hombre, la comunidad política
} 
empresa un mayor protagonismo, se sostiene siempre y cuando no perdamos con ello de vista la premisa mayor de nuestro razonamiento aquí, a saber, que no existe ninguna reconstrucción histórica "privilegiada" de la dialéctica de la Modernidad que asegure un acceso "objetivo" a la lógica de los grandes conceptos morales y políticos modernos, que a la postre no son sino una pluralidad de conceptos aporéticos de los que salieron a flote las perspectivas respaldadas por el poder establecido.

Si alguna repercusión clara han tenido las décadas de crítica postmoderna es justamente ésta: el haber hecho añicos el espejo en que se miraba la historia universal como una verdad absoluta, para propiciar el surgimiento de una pluralidad de historias que nos permiten descubrir planteamientos que en un momento dado quedaron en la sombra y que, paradójicamente, en otro momento contribuyen a arrojar luz sobre una determinada problemática, o, más precisamente, a adoptar una perspectiva distinta sobre argumentaciones pasadas, aguijoneados por problemas de actualidad. En este sentido, tanto el diagnóstico (teoría de la historia conceptual) como la prognosis (práctica de la misma) pasan por la relación de implicación (tanto epistemológica como política) que tenemos con nuestros intereses presentes. Como escribiera C. Thiebaut al respecto: "Los clásicos son la otra cara del presente... Los clásicos no existen por sí mismos, o sólo existen en una inquietante neutralidad, como si no fueran tanto textos cuanto pretextuales, a la espera del acto lector interesado que les suministre actualidad, vigencia y sentido y deben su ser al afán de construcción del presente por medio de la construcción de un pasado"11.

La historia, la interpretación que de ella hace la filosofía de la historia no es nada sin los protagonistas que le dieron vida. De manera que al alejarnos de una concepción de la filosofía de la historia "unilineal" y "profética" no sólo reivindicamos un futuro indeterminado y contingente, sino también un pasado abierto, como ya sugiriera Arthur Danto ${ }^{12}$. Ahora bien, el alejamiento de una

\footnotetext{
y la ciencia del ámbito práctico. Cf. La rappresentanza politica: genesi e crisi del concetto, Franco Angeli, Milán, 2006.

${ }^{11}$ Cf. Cabe Aristóteles, Visor, Madrid 1988, p. 17. No muy alejado de esta perspectiva escribía Leibniz en Preceptes pour avancer les sciences: "J'ay trouvé apres de longues recherches qu'ordinairement les opinions les plus anciennes et les plus receues sont les meilleurs, pourveu qu'on les interprete equitablement", GP VII, 164.

12 "We are always revising our belifs about the past, and to suppose them 'fixed' would be unfaithful to the spirit of historical inquiry" Analytical Philosophy of History, Cambridge University Press, London\&New York, 1965, 145.
} 
interpretación determinista y universalista de la historia no significa abrazar un relativismo absoluto, ni sostener que no puedan descubrirse en los análisis históricos de los conceptos estructuras que nos permitan explicar mejor que otras el desarrollo de los acontecimientos pasados o futuros: por ejemplo, el hecho de que en los denominados "momentos de crisis" se vuelva a los filósofos antiguos (Platón, Aristóteles) es una constante que nos resulta ya familiar en la historia intelectual de la Modernidad. Se trata más bien de una precaución profesional práctica: no creamos nadie estar a salvo en nuestras interpretaciones de las ideologías e intereses que nos dominan. No existen ni el observador ni el cronista ideal y, menos aún, el intérprete objetivo de la historia por antonomasia. Cada historia es "una historia más", que acaso contribuya a iluminar un poco más desde su perspectiva de la problemática subyacente a los vaivenes conceptuales de la Modernidad heredada: como subrayaba Madame de Staël en sus comentarios sobre la Revolución Francesa "las luces solo se curan con más luces"13.

\section{Anticipación leibniziana de cierta historia conceptual ${ }^{14}$}

Como he venido subrayando en mis trabajos anteriores sobre Leibniz, frente a la simplificación y encasillamiento que se suele hacer de él en las historias de la filosofía, la complejidad y riqueza argumentativa de este pensador, su talante multidisciplinar, su curiosidad por todos los campos del saber y todas las culturas, permiten descubrir en su filosofía elementos esclarecedores para la reordenación de nuestras reflexiones filosóficas sobre la historia y del mismo concepto de racionalidad. El afán de Leibniz consistía en conectar las distintas ciencias para que cada una se enriqueciera gracias a las demás, formando una especie de tejido o retícula en la que todo tenía que ver con todo, superando esa barrera especializadora que tanto lamentan actualmente filósofos de la ciencia e historiadores de las ideas, pero sobre todo, haciendo de la actividad humana, de su transformación de la realidad y de las instituciones en aras de la consecución

\footnotetext{
${ }^{13}$ La frase ha sido sobre todo citada en contextos feministas, para poner de manifiesto la incompletitud de una ilustración que no incluía a la mitad del género humano, pero de la que sin embargo no se debía hacer caso omiso, como han subrayado Celia Amorós y Amelia Valcárcel en sus escritos. Cf. por ej. C. Amorós, Tiempo de feminismo: sobre feminismo, proyecto ilustrado y postmodernidad, Cátedra (Colección Feminismos), Madrid, p. 436.

${ }^{14}$ Una primera versión de esta tesis apareció en el trabajo "Ilustración y semántica histórica", en F. Oncina, Teorias y prácticas de la historia conceptual, Plaza y Valdés/CSIC, MéxicoMadrid, pp. 393-422.
} 
de una mayor felicidad, la meta de toda sabiduría, como muy bien refleja su lema "Theoria cum praxi". Ahora bien, lo que sin duda hace a Leibniz atractivo a la hora de encarar el problema de la racionalidad es que, en ese momento crucial de la "Disputa entre antiguos y modernos", él sabe compatibilizar sus propuestas innovadoras con un diálogo crítico con la filosofía precedente, como con los filósofos que gustamos de recordar como iniciadores de la Modernidad (Descartes, Spinoza, Malebranche, Hobbes, Locke, Thomasius, Wolff, Newton, etc.), comportándose como un auténtico hermeneuta, pues no se conforma con contraponer a sus adversarios lo que considera una teoría más potente, sino que también explica el atractivo que reviste el modelo que critica, desde un perspectivismo que en nuestros días le hace si cabe más encomiable, con la finalidad de iluminar y completar los saberes teóricos, orientando los prácticos. Podríamos decir sin temor a equivocarnos, como han subrayado Quintín Racionero y Marcelo Dascal ${ }^{15}$, que lo mejor del pensamiento de Leibniz se forja al hilo de las controversias mantenidas con sus coetáneos.

Ciertamente, y en esto coincidiría nuestro análisis con el de Koselleck, algunos de los conceptos de la metafísica leibniziana llevados a sus últimas consecuencias se convirtieron en el humus sobre el que se levantó el edificio de la filosofía clásica de la historia, que tanto hemos criticado; estas reflexiones ocuparán el siguiente apartado, que podríamos calificar como "la herencia conceptual negativa de Leibniz". Ahora bien, y ésta será mi apuesta en el siguiente apartado, hay otra familia de conceptos leibnizianos que sirven también de base a la Modernidad y que constituyen la otra cara de la Ilustración -la cara amable si así se prefiere, que también he caracterizado de "herencia positiva"- en la que los conceptos de contingencia, libertad, tolerancia y pluralismo se dan la mano para zafarse del encorsetamiento determinista a que parecía condenada la historia de la humanidad, bien por naturaleza, bien por convención. Si los primeros conceptos se presentan como "persistentes" durante casi dos siglos ${ }^{16}$, los segundos supieron ser "resistentes" y sobrevivir en corrientes subterráneas del pensamiento hasta poder emerger con toda su fuerza en nuestros pensamientos contemporáneos ${ }^{17}$.

${ }^{15}$ Cf. G. W. Leibniz. The Art of Controversies, Springer, The Netherlands, 2006. Libro que fuera resultado de las investigaciones realizadas en la UNED de Madrid en el marco del proyecto de investigación que sobre el tema de las controversias coordinara Quintín Racionero. ${ }^{16}$ Cf. C. Roldán y O. Moro (eds.), Aproximaciones a la contingencia. Catarata, Madrid, 2009. ${ }^{17}$ Cf. "La idea de tolerancia en Leibniz", en Forjadores de la tolerancia, Ma José Villaverde and John Ch. Laursen (eds.), Tecnos, 2011, pp. 162-180. Cf. también "A Leibnizian Way to Tolerance: Between Ethical Universalism and Linguistic Diversity", en Paradoxes of Religious Toleration in Early Modern Political Thought (ed. by J. Ch. Laursen and Ma J. 
Pero tanto unos como otros son deudores de esa modernidad que pervive, más o menos agónica, en nuestros días. Esto es lo que nos legitima, a mi entender, para poder hablar no sólo del protagonismo, sino también de la actualidad de Leibniz, la cual (aparte de sus grandes intuiciones científicas que van reconociéndosele hoy día poco a poco) reside precisamente en una "actitud racional", que me parece digna de tener en cuenta en nuestros planteamientos, en los que la fragmentación desemboca a veces en una excesiva simplicidad. En este sentido, he subrayado en la introducción de mi último libro sobre Leibniz ${ }^{18}$ la idea del desconocimiento de su pensamiento, cuando en realidad se anticipa a muchos de los planteamientos contemporáneos desde su propia perspectiva del momento.

\section{Conceptos que la filosofía clásica de la historia hereda de Leibniz}

La reflexión sobre la historia -que durante siglos nos ha sido dada a conocer como "filosofía de la historia"- es un fenómeno genuinamente ilustrado. Ciertamente, toda periodización que se establezca en la presentación de cualquier historia de la filosofía es arbitraria, pero, aunque no podamos defender rupturas absolutas, es evidente que en un momento determinado de la misma se dan las condiciones adecuadas para que se manifieste un modo de pensar que antes había ido gestándose sin tener el empuje necesario para aflorar a la superficie. En este sentido, aunque podemos hablar de una prehistoria en la reflexión sobre la historia ${ }^{19}$ tanto en el mundo antiguo y medieval como en el Renacimiento y en los comienzos de la Modernidad, la filosofía de la historia -entendiendo por tal un modo de pensar reflexivo y crítico- hace por primera vez acto de presencia en

\footnotetext{
Villaverde), Lexinton Books: Lanhan, Boulder. New York, Toronto, Plymouth, UK, 2012, pp. 91-107. Precisamente el tema de la tolerancia fue el escogido para la celebración del II Congreso Iberoamericano de Filosofía en Perú, bajo la coordinación de Miguel Giusti. Yo no pude asistir pero me consta que Quintín Racionero presentó una conferencia que lamentablemente solo llegó a mis manos cuando mi manuscrito ya estaba en imprenta; está publicado en Tolerancia, colección de cinco volúmenes de las actas del XV Congreso Interamericano y II Congreso Iberoamericano de Filosofía, editadas por M. Giusti (2011); es otra conversación pendiente.

${ }^{18}$ Cf. C. Roldán, Leibniz. En el mejor de los mundos posibles, Batiscafo, Barcelona, 2015 (con traducciones publicadas al portugués e italiano).

${ }^{19}$ He desarrollado esta cuestión en el primer capítulo de mi libro Entre Casandra y Clío, "La prehistoria de la filosofía de la historia”, Akal, Madrid, 1997 (2a ed. 2005), pp. 19-46.
} 
la Ilustración. Pero esto es posible, a mi entender, por la gestación previa en los orígenes de la modernidad (que Max Wundt denominara "Ilustración temprana" o "primera Ilustración" ${ }^{20}$ ) de algunos conceptos genéricos como racionalidad, humanidad, libertad y progreso, pero sobre todo del cambio de signo de algunos otros conceptos, que trasladan su significado genuinamente filosófico (incluso metafísico) al ámbito de la reflexión histórica. Lo que, en otro orden de cosas, supondrá un paso importante en el desarrollo de un método que permita garantizar la veracidad de los relatos históricos, un método documental basado en la filología ${ }^{21}$.

Ya he insistido en otros trabajos sobre lo que considero una de mis aportaciones fundamentales a la interpretación leibniziana en relación con la filosofía de la historia, a saber, la colaboración del pensador de Leipzig en lo que he venido denominando "línea dominante - o triunfante- de la filosofía de la historia", fundamentalmente representada por autores como Kant y Hegel -pero también Comte o Marx- y en cuyo origen podríamos situar algunos conceptos leibnizianos que inspiran esa filosofía especulativa de la historia "determinista", "finalistalineal" e "inevitable", como caracterizó I. Berlin y que yo identifico con una "herencia negativa de Leibniz. A mi entender, Leibniz no lleva a cabo una filosofía de la historia determinista”, como en la que insistirá la filosofía clásica de la historia, aunque algunos intérpretes han puesto de manifiesto que es a él a quien debemos "la idea de la filosofía como una tradición histórica continuada"22, si no que más bien insiste en los aspectos históricos de la contingencia a la que nos referiremos después; sobre la relevancia de este aspecto anti-determinista en la filosofía de la historia en Leibniz han insistido buenos conocedores de Leibniz como Davillé, Fischer o Hübener ${ }^{23}$, o donde los avances no obedecerían tanto a

${ }^{20}$ Cf. Die deutsche Schulphilosophie im Zeitalter der Aufklärung, Olms, Hildesheim, 1945. M. Wundt defiende un concepto amplio de ilustración que no se restringe al siglo XVIII. Cf. también al respecto, C. Roldán, "La aurora de la filosofía de la historia", en Entre Casandra y Clío, p. 47 y ss.

${ }^{21}$ Cf. J.C. Bermejo y P.A. Piedras, Genealogía de la historia, Akal, Madrid, 1999, pp. 36-37.

${ }^{22}$ Cf. A. Heinekamp, "Die Rolle der Philosophiegeschichte in Leibniz' Denken”, in Ibid., pp. 114-141.

${ }^{23}$ Louis Davillé fue el primero en poner sobre la mesa esta interpretación de la filosofía de la historia de Leibniz; en su conocida obra Leibniz Historien (Paris, 1909, p. 666), en el capítulo dedicado a la filosofía de la historia, afirma taxativamente que Leibniz nunca investigó acerca del encadenamiento de las causas y de los efectos en historia, como luego lo harían algunos discípulos suyos como Herder, ni tampoco se dedicó, por otra parte, a intentar deducir las leyes generales que rigen los fenómenos históricos. Convicción esta en la que insistirán otros especialistas como Kuno Fischer, G.W. Leibniz, Heidelberg, 1920, p. 764 y Wolfgang 
la instauración de ideas nuevas y revolucionarias, lo que en lenguaje de nuestros días denominaríamos "innovación" y que hace pie en el ars inviniendi leibniziano, como a la conservación de lo que él denominó "filosofía perenne" y que se apoyaría más bien en el ars demostrandi. Sobre esta cuestión incidieron algunos sobresalientes representantes de la filosofía de la historia en los siglos XIX y XX, como Robert Flint, quien afirmaba que la filosofía de Leibniz "fue la primera que se penetró entera y profundamente del espíritu de la historia”, debido a su comprehensión y universalidad ${ }^{24}$, o como Friederich Meinecke, que llegó a incluir a Leibniz entre los precursores del historicismo ${ }^{25}$, por la idea de individualidad que defiende en su filosofía, como referente de "un individuo fuerte" que actúa y se desarrolla o despliega según sus leyes y el cual, por otra parte, coincide con una ley universal, expresión de la armonía universal y en la que no podemos evitar ver trazos de un cierto determinismo.

Es cierto que en el planteamiento leibniziano se presentan relacionadas la historia y la filosofía, que desde la antigüedad se presentaban como extrañas e incluso enfrentadas ${ }^{26}$, si bien Leibniz subraya las diferencias existentes entre las dos disciplinas y sus objetos, pues mientras la historia es un conocimiento que se refiere -o debería referirse, podríamos añadir- a las cuestiones de hecho o singulares, cuyo conocimiento necesita también de la experiencia y de la memoria y no sólo de la razón, que basta a una filosofía concebida como ciencia demostrativa y que se refiere a las cosas posibles y necesarias, como recuerda Leibniz en sus Nuevos ensayos y en otros textos ${ }^{27}$.

A lo largo de su vida, Leibniz tuvo que ocuparse de trabajar como historiador, recopilando los datos de la familia Braunschweig, tarea que a veces se le llega a presentar como ominosa, sobre todo al final de su vida, cuando la ve como impedimento para realizar otras dos tareas que él consideraba prioritarias en su

Hübener, "Leibniz - ein Geschichtsphilosoph?", en Leibniz als Geschichtsforscher, Studia Leibnitiana, Sonderheft 10, 1982, 38-48. Cf. Q. Racionero, "Ciencia e historia en Leibniz", en Revista de filosofía 2 (1989), pp. 127-154.

${ }^{24}$ R. Flint, The philosophy of history in France and Germany, William Blackwood and Sons, Edinburgh and London, 1874, Book II, p. 344.

${ }^{25}$ Cf. F. Meinecke, Die Entstehung des Historismus, Leibniz Verlag, München, 1946, pp. 34-35.

${ }^{26}$ Lo que no parece haber cambiado sustancialmente en la actualidad, donde todavía escuchamos ecos de la polémica entre historiadores y filósofos, que se agudizara en el siglo pasado. ${ }^{27}$ Cf. G.W. Leibniz, Nouveaux Essais sur l'entendement humaine, III, 5. Vgl. a. C, 524. Cf. también De fine scientiarum, en Grua, I, 240. Cf. también Couturat, Opusc., p. 524. Cf. De fine scientiarum, en Grua, Textes inédits, I, p. 240. 
desarrollo intelectual y político: la culminación de la característica universal y la reunificación de las iglesias. Pero, si le interpretamos bien, su interés por la crítica histórica no procede tanto de su tarea como historiador, sino más bien de la aplicación de sus métodos de investigación al estudio de la historia de la filosofía, siendo revolucionaria la conexión que establece entre los estudios filológicos y los históricos ${ }^{28}$. Aunque podemos afirmar sin temor a equivocarnos que su aportación más innovadora descansa en su concepción filosófica misma, donde aparecen apuntadas algunas ideas que luego serán desarrolladas por los primeros filósofos de la historia a mediados del siglo XVIII; en este sentido es como podemos entender las palabras de J. Thyssen cuando afirma que "podría sostenerse la tesis de que en Herder encontramos la filosofía de la historia propia de la metafísica de Leibniz" ${ }^{29}$.

Robert Flint habla en la obra anteriormente mencionada de algunas concepciones de la filosofía leibniziana que habrían sido después "transportadas" a la filosofía de la historia, en concreto, se refiere a la ley de analogía, la ley de continuidad, el vitalismo, la teoría general de la armonía preestablecida y el optimismo, pero afirma no le parece pertinente discutir de algo de lo que Leibniz mismo no hizo la aplicación histórica ${ }^{30}$. Por mi parte, no sólo encuentro pertinente hablar de ello, sino que considero que son algunos principios metafísicos de la filosofía leibniziana como los de continuidad y armonía universal, pero sobre todo el de perfección ${ }^{31}$, los que se sitúan a la base de la idea de progreso hacia lo mejor que constituye una de las características definitorias de la filosofía especulativa de la historia. A mi entender, será justamente el entramado de esos tres principios -continuidad, armonía y perfección- lo que proporcionará un claro antecedente a esa versión laica y racional de la providencia que en Kant se presentará como "intención oculta de la naturaleza" y en Hegel como "astucia de la razón", que para el mismo Leibniz se presentará ya como traducción secularizada de la idea de una providencia divina, encargada de introducir orden y

${ }^{28}$ Cf. R. Flint, op. cit., p. 21.

${ }^{29}$ Cf. op. cit. p. 58. La influencia de Leibniz en la filosofía de la historia no sólo deja sentirse en el s. XVIII, sino que se prolonga a través de Hegel durante todo el XIX; pensadores como Comte, Marx e incluso Darwin citaron a Leibniz en momentos importantes de la exposición de sus ideas. Sobre la presencia de Leibniz en la filosofía de la historia de Kant, cf. C. Roldán, "Le fil d'Ariane de la détermination rationelle et les enchevêtrements de Cassandre", en D. Berlioz et F. Nef (éd.), L'actualité de Leibniz : Les deux Labyrinthes, Studia Leibnitiana Supplementa 34, 1999, pp. 55-68.

${ }^{30}$ Cf. op. cit. pp. 21-22.

${ }^{31}$ Sobre el principio de perfección, cf. C. Roldán, "Das Vollkommenheitsprinzip bei Leibniz als Grund der Kontingenz”, en Studia Leibnitiana XXI/2 (1989), pp. 188-195. 
continuidad en el desarrollo contingente de los acontecimientos históricos, esto es, una armonía universal apoyada en los principios de razón suficiente y perfección. Algo que es posible en el pensamiento leibniziano, como mencionábamos más arriba, porque todos los seres del universo siguen espontáneamente sus propias leyes finales -tesis de la noción individual de cada sustancia que escandalizó a Arnauld, pues contiene de una vez por todas todo lo que le acontecerá-, aunque no puede calificarse de determinista, pues este mismo despliegue alcanza en los seres humanos un grado de libertad, esto es, de "determinación racional al bien", de forma que puede llegar a afirmarse que "el presente está preńado de futuro" 32 sin que ello signifique ausencia de libertad responsabilidad ética. Pues el mejor de los mundos posibles leibniziano no es una realidad acabada más que para la previsión de una mente absolutamente perfecta que puede conocer mediante la intuición, mientras que los seres humanos -con un entendimiento discursivo que se despliega en el tiempo y espacios relacionales- están llamados a promover desde su libertad el progreso moral de la humanidad ${ }^{33}$, contribuyendo a mejorar, por así decir, continuamente el mejor de los mundos posibles. Sólo desde esta interpretación podemos entender cómo en su correspondencia con Bourguet afirma Leibniz que su hipótesis de que vivimos en el mejor de los mundos posibles es compatible con otra hipótesis, a saber, la del progreso de la humanidad; para explicar esta aparente contradicción, recurre Leibniz a la distinción conceptual entre dos tipos de perfección, la "metafísica" y la "moral", de manera que aunque el mundo tomado en su conjunto -esto es, considerado como posible en el entendimiento divino- conserve siempre la misma cantidad de perfección, lo que lo convertiría en necesario, por otra parte es susceptible de perfectibilidad a lo largo de un proceso infinito, gracias al avance progresivo de las artes y las ciencias, lo que le permite decir en el $\$ 341$ de los Ensayos de Teodicea: "E incluso puede suceder que el género humano llegue con el tiempo a una mayor perfección que la que podemos imaginar ahora" ${ }^{4}$. Desde su punto de vista, y en virtud del principio de continuidad, la extensión gradual de la civilización se lleva a cabo de manera constante, a pesar de las aparentes etapas de estancamiento e incluso de retroceso, pues "si se retrocede es para saltar

\footnotetext{
${ }^{32}$ Cf. C. Roldán, "La salida leibniziana del laberinto de la libertad", G. W. Leibniz. Escritos en torno a la libertad, el azar y el destino, Tecnos, Madrid, 1990, pp. IX-LII.

${ }^{33}$ Sobre la idea de progreso en Leibniz, cf. C. Roldán, "El principio de perfección y la idea de progreso moral en Leibniz", en Il cannocchiale. Rivista di Studi filosofici (1992), pp. 25-44.

${ }^{34}$ G.W. Leibniz. Obras filosóficas y cientificas (OFC) 10, ed. por Tomás Guillén Vera, Comares, Granada, 2012, 324.
} 
mejor" ${ }^{35}$, de forma que incluso los mayores males y desgracias -las disonancias en la historia- revertirán en nuevos progresos hacia el bien -la armonía del mejor de los mundos posibles. Así, desde mi punto de vista, puede afirmarse que los conceptos de perfección y continuidad de Leibniz conforman la idea de progreso ilustrada, lo mismo que su concepción de racionalidad y armonía constituyen los fundamentos de la explicación histórica; estos son los conceptos básicos que constituirán el fundamento de la filosofía especulativa de la historia, sobre todo en la ilustración y el idealismo alemanes.

\section{Conceptos leibnizianos para la rehabilitación de una filosofía crítica de la historia}

Según acabamos de ver, Leibniz se convierte en el inspirador de la filosofía clásica de la historia, con unos conceptos que podemos calificar como "rígidos". Pero en el pensamiento leibniziano podemos rastrear también otro grupo de conceptos que podemos denominar "flexibles" ${ }^{36}$ y que contribuyen a introducir diversidad, gradualismo y un cierto pragmatismo ${ }^{37}$ en nuestras reflexiones y experiencias. Esos conceptos no son otros que los de "contingencia", "libertad" (autonomía) y "tolerancia”, y se encuentran todos ellos bajo el paraguas de un principio más amplio, el de "pluralidad", que Leibniz enuncia como "perspectivismo" desde un punto de vista ontológico-gnoseológico en su Monadología ${ }^{38}$. Así, la pluralidad de puntos de vista desde los que puede contemplarse

\footnotetext{
${ }^{35}$ De rerum originatione radicali, GP VII, 308, en francés en el original: "qu'on recule pour mieux sauter". Cf. G.W. Leibniz, OFC 2, 285.

36 Prefiero optar por un concepto como "racionalidad flexible", frente al de "racionalidad blanda” empleada por Marcelo Dascal apoyándose en un texto en el que el pensador de Leipzig habla de "blandior ratio".

${ }^{37}$ Cf. al respecto los excelentes artículos de Txetxu Ausín: "Weighing and gradualism in Leibniz as instruments for the analysis of normative conflicts" (Studia Leibnitiana XXXVII/1, 2006, 99-111) and "The Quest for Rationalism without Dogmas in Leibniz and Toulmin" (D. Hitchcock \& M. Verheij (eds.) Arguing on the Toulmin model New Essays in Argument Analys and Evaluation, Dordrecht, Springer, 2006, 261-272).

38 "Y como una misma ciudad contemplada desde diferentes lados parece enteramente otra y se halla como multiplicada en lo que respecta a su perspectiva, también ocurre que debido a la multitud infinita de las sustancias simples, hay como otros tantos universos diferentes que, sin embargo, no son más que las perspectivas de uno solo según los diferentes puntos de vista de cada mónada”, Monadologie $\$ 57$ (GP VI, 616; OFC 2, 336). Cf. al respecto Nouveau System $\$ 14$ (GP IV, 484 ; OFC 2, 246-247). Una primera aproximación a estas reflexiones
} 
la ciudad, expresan metafóricamente una peculiar "racionalidad hermenéutica" en Leibniz, que se reconoce por esforzarse en captar la parte de verdad presente en cada perspectiva de la realidad, tal y como el propio Leibniz insistió siempre en hacer en su propia filosofía, mal definida como "eclecticismo"; Leibniz siempre y contra corriente insiste en conservar la perspectiva de la "filosofía de los antiguos" (cuando todos defienden la nueva filosofía cartesiana), o la filosofía de los otros hombres doctos del momento, o la de las otras variantes del cristianismo, o la de las otras culturas ${ }^{39} .$. Se trata de un pluralismo que, sobre la base de su concepción de la contingencia y la individualidad, proporciona su fundamento a la idea de tolerancia, con tintes cosmopolitas e incluso multiculturales. La pluralidad de perspectivas será la mejor salvaguarda para aproximarse a la verdad libres de prejuicios y dogmatismos, no primando ninguna de ellas; sin embargo, en esta aproximación habrá que encontrar también un camino intermedio que no conduzca al relativismo, uno de los anatemas a que se opuso Leibniz de por vida.

En la concepción del saber leibniziano se dan cita dos maneras de aproximarse a los conocimientos y a la realidad, que el denomina ars demostrandi y ars inviniendi, dependiendo de si podemos deducirlos a priori de axiomas primeros -evidentes y no contradictorios, por simplificar- o, por el contrario, precisan de la creatividad humana para ganarse un lugar entre los conocimientos. Este movimiento epistemológico, que va de lo conocido a lo desconocido, no es muy diferente a mi entender de la metodología que emplea la semántica histórica en su análisis y definición de conceptos, y que constituye el fundamento de lo que he dado en llamar "nueva filosofía de la historia" ${ }^{40}$, que no puede por menos que evocarnos a la pareja de herramientas conceptuales denominadas por Koselleck "espacio de experiencia" y "horizonte de expectativas".

No debemos olvidar que la metodología que emplea Leibniz no sólo en sus consideraciones filosóficas más abstractas sino también en sus investigaciones históricas, y en sus estudios sobre el origen de las lenguas y a característica

aparecieron en mi artículo publicado en Isegoría 17 (1997) bajo el título "Theoria cum praxi: la vuelta a la complejidad (Apuntes para una filosofía práctica desde el perspectivismo leibniziano)", pp. 85-105.

${ }^{39}$ Cf. C. Roldán, "Las raíces del multiculturalismo en la crítica leibniziana al proyecto de paz perpetua”, en Saber y conciencia, J.A. Nicolás y J. Arana (eds), Comares, Granada, 1995, pp. 369-394.

${ }^{40}$ Me inspiro para esta denominación en Hyden White y Frank Ankersmit eds. y su "constructivismo narrativista", que también preconizara Arthur Danto, con su "filosofía analítica de la historia”. Cf. C. Roldán, Entre Casandra y Clío, loc. cit. pp. 177-182. 
universal, proviene de su concepción de "hipótesis metafísica". Uno de los ejemplos más claros de hipótesis metafísica en el pensamiento de Leibniz lo encontramos en su teoría de la "armonía preestablecida", a la que siempre se refiere en sus escritos como "hipótesis" o "supuesto" ${ }^{1}$, cuando, como él mismo afirma, "establecer una hipótesis o explicar el modo de generación de algo no es más que demostrar la posibilidad de ese algo" ${ }^{\prime 2}$. Así pues, puesto que la primera condición de la posibilidad de una proposición o de una cosa es su ausencia de contradicción, en aquellas demostraciones que proceden de proposiciones concedidas o de hipótesis, lo primero que hay que hacer es mostrar qué hipótesis se contradicen entre $s i^{43}$. Ahora bien, una vez demostrada la coherencia interna, esto es, que la argumentación se desarrolla en una debida forma lógica, no puede olvidarse que las conclusiones obtenidas son hipotéticas ${ }^{44}$, lo que en lenguaje popperiano equivaldría a afirmar que "están sujetas a la falsación"; lo que es lo mismo que afirmar, en el ejemplo que barajábamos, que la "hipótesis metafísica de la armonía preestablecida" ha de ser considerada como una hipótesis más que concursa con el resto (por ej. la "hipótesis de las causas ocasionales") en la explicación de la posibilidad de las cosas.

En este carácter contingente o "flexible" del discurso leibniziano radica precisamente su vinculación con una filosofía de la historia no determinista, en la que las "explicaciones plausibles" son las que ocuparían el lugar predominante, lo que nos permite afirmar que para Leibniz los sucesos históricos, lo acaecido, sólo puede tener lugar en el supuesto de que Dios exista y haya creado este mundo, pues entonces y sólo entonces -no olvidemos el subtítulo de los Ensayos de Teodicea: sobre la bondad de Dios, la libertad del hombre y el origen del mal-habría que justificar la bondad de Dios y la existencia del mal en el mundo. De esta manera, haciendo el esfuerzo hermenéutico de poner esa perspectiva trascendente entre paréntesis y adoptando la pluralidad de perspectivas del mundo existente, comprenderemos que lo mismo sea considerado por Leibniz como "hipotéticamente necesario" desde el punto de vista de lo absoluto y como "absolutamente contingente" desde la perspectiva humana. Dicho con otras palabras, esto no significa otra cosa que afirmar que su talante racionalista no le impide a Leibniz priorizar la importancia de la experiencia a posteriori, que en los seres humanos

${ }^{41}$ Cf. Nouveau System $\$ 15$ (GP IV, 485, OFC 2, 247-248) o Monadologie $\$ 59$ (GP VI, 616, OFC 2, 336). Cf. también GP I, 149 : "... per suppositionem sive hypothesin...".

${ }^{42}$ De Synthesi et Analysi universali seu Arte inviniendi et judicandi, GP VII, 295.

${ }^{43}$ Cf. De principiis (post. a 1683), en Couturat, Opusc., 184.

${ }^{44}$ Meditationes de Cognitione, Veritate et Ideis, GP IV, 426. 
suple en la mayoría de los casos a las razones a priori, lo que le llevará a afirmar que la libertad humana es un factum, que no está sujeta a ningún determinismo y que cabe elegir el mal, esto es, como ha subrayado Quintín Racionero en sus trabajos, que, "la hipótesis que hay que demostrar es la de la necesidad y no la de la libertad" 45 .

\section{A modo de conclusión: De la historia conceptual como arsenal de conceptos morales y políticos a la filosofía de la historia como responsabilidad ética}

Todo lo que forma parte del universo es contingente, pero lo que es contingente por antonomasia es la historia, es decir, aquello que depende inmediatamente de la acción humana, que consigue en gran medida zafarse del determinismo natural, porque los seres libres o inteligentes no están atados a leyes subalternas determinadas del universo, sino que actúan por la sola espontaneidad de su propia potencia. ${ }^{46} \mathrm{Y}$, desde luego, Leibniz está convencido de poder intervenir en la realidad histórica: de ahí sus actividades políticas para contribuir a la reunión de las iglesias, o sus empresas de fundación de Academias científicas. En este orden de cosas, la teoría leibniziana de la libertad ${ }^{47}$ será, pues, una teoría de la acción que no puede conformarse con ganar espacio al determinismo natural, sino que apunta a lo que realmente puede hacer el ser humano, a esa creatividad radical que sale de su propio fondo plasmándose en controversias teóricas que adquieren su validez de su capacidad para influir en la práctica. La contingencia no es, pues, sólo un principio metafísico, sino ante todo un principio moral, que posibilita la libertad de los sujetos y, como

45 "La racionalización de la política", Revista latinoamericana de filosofía XVIII, n 1 , otoño 1992 , p. 96.

${ }^{46}$ Leibniz afirma, criticando el Art. 6 de los Principia de Descartes: "No tenemos libre arbitrio al percibir, sino al actuar" (GP IV, 357). Cf. Verdades necesarias y contingentes, VE 3, 459 (Olaso, 333). A esto denominará Kant "causalidad por libertad".

${ }^{47}$ Las conversaciones en torno a la libertad en Leibniz fueron uno de mis temas favoritos de conversación con Quintín Racionero, desde la defensa de mi tesis doctoral Contingencia y necesidad. El problema de la libertad en Leibniz (1987), en cuyo tribunal estuviera Quintín. Por eso resulta entrańable ver que ambos escogimos este tema para homenajear a nuestro común amigo, Manuel Fraijó, en Pensando la religión (Trotta-UNED, Madrid, 2013): el uno bajo el título "La noción de libertad racional en Leibniz y sus consecuencias para el problema del mal" (pp. 412-447), la otra como "Teodicea y libertad en Leibniz: del mal radical al bien común” (pp. 448-464); este fue el último trabajo que mando a la imprenta en vida. 
consecuencia, la imposibilidad de predicción de sus acciones. En este sentido, a lo largo de sus escritos se opondrá Leibniz a la idea de que toda actividad del hombre sea inútil porque todo ocurra inevitablemente, esto es, la concepción clásica del destino que Crisipo había caracterizado como "argós logós", es decir, la "razón perezosa" recogida en el mundo mahometano, por la que "todo lo que ha de ocurrir, ocurrirá necesariamente obres o no obres", hagas esto o aquello. Para el pensador de Leipzig, por el contrario, la acción humana no sólo es libre, sino que se dice de muchas maneras y de ella depende la historia humana, individual y social.

No es casualidad que en este trabajo dedicado a la memoria de Quintín Racionero, quiera concluir dedicando unos párrafos a la actualidad de Leibniz en la importancia ético-política de unos conceptos que configuran una tendencia en el pensamiento humano de la modernidad heredada, sin por ello querer erradicar un pluralismo que, más bien al contrario, estaría fomentado por el pensador de Leipzig, utilizando como contrapunto avant la lettre ese germen del concepto de "espacio de experiencia" que fue el concepto de "crisis" para el primer Koselleck. A mi entender, tanto a Leibniz como a Koselleck el concepto de "crisis" 48 les sirve para referirse a un cambio de época, a la ruptura entre la antigüedad y la modernidad; un concepto el de crisis que zarandea a los individuos impidiéndoles dormirse en los laureles de su experiencia de la continuidad, y que aún sigue zarandándoles de manera pluscuamperfecta. Los dos autores, sin embargo, se resisten al cambio y dedican sus esfuerzos reflexivos a levantar una estructura conceptual que dote a la nueva época de una "racionalidad común", que ponga brida a unos conceptos que parecían cobrar vida propia, irrumpiendo con decisión en la historia socio-política... El protagonismo de los conceptos parecía introducir en la historia de la humanidad -por la puerta trasera- un determinismo cuyo yugo se había sacudido la propia historia natural. Y la única manera de plantar cara a ese torbellino semántico parecía ser la historia conceptual, esto es, dedicarse a entender la génesis, la lógica de los conceptos escondida tras las palabras tan cargadas de significados..., escudados en la convicción de que las ideas no tienen poder de actuación al margen de la mente misma (mens agit, ideae non agunt, subrayaba Leibniz).

\footnotetext{
${ }^{48}$ Cf. P. Hazard, La crise de la conscience européenne: 1680-1715, Paris, 1935; hay traducción castellana en Alianza Editorial, Madrid, 1988. Cf. asimismo Koselleck, Crítica y crisis, loc. cit.; y la voz "Krisis" de los Geschichtliche Grundbegriffe, también traducida al cast. por J. Pérez de Tudela.
} 
Ahora bien, una tarea que se quiere reflexiva y crítica no puede hacer tabula rasa de los problemas del pasado, de esos mismos problemas que los conceptos definen, pero nunca de manera neutra, siempre otorgándoles un valor, positivo o negativo. Y es ahí donde la historia conceptual tiende la mano a una nueva filosofía crítica de la historia, que -modestamente y desde la contingenciaquiere "hacerse cargo" de los conceptos morales y políticos, para impedir en la medida de lo posible, el debilitamiento, la deformación y el vaciamiento que están sufriendo los mismos en manos de ideologías neoliberales y conservadoras, simplificadoras de lo humano. Cuando todo lo sólido se desvanece en el aire ${ }^{49}$, los sujetos individuales y colectivos se rebelan contra el peso inerte de los grandes conceptos vaciados de contenido (libertad, igualdad, solidaridad, progreso, democracia), que se agitan sin más como un mantra sinsentido, y se proponen "hacer cosas con conceptos", esto es, recuperar el sentido de una filosofía crítica de la historia que es a su vez filosofía de la acción.

\footnotetext{
${ }^{49}$ Bajo ese título, tomado del Manifiesto comunista (1848) de K. Marx y F. Engels, Marshall Berman publicó en 1982 en Nueva York un libro en el que pretende detectar en qué punto se desvió la modernidad de sus verdaderos propósitos de progreso y emancipación colectiva. No podemos obviar que en las últimas décadas estamos asistiendo a una vuelta a Marx; cf. por ej. uno de los últimos números monográficos de Isegoría. Revista de filosofia moral y política (50, 2014).
} 


\section{Bibliografía}

Amorós, C.; VAlcárcel, A. (1997). Tiempo de feminismo: sobre feminismo, proyecto ilustrado y postmodernidad. Madrid: Cátedra (Colección Feminismos).

Andreu, A. (1997). Ilustración e Ilustraciones. Valencia: Universidad Politécnica de Valencia.

Ausín, T. (2006). "Weighing and gradualism in Leibniz as instruments for the analysis of normative conflicts", Studia Leibnitiana XXXVII/1, pp. 99-111.

- (2006). “The Quest for Rationalism without Dogmas in Leibniz and Toulmin”, en D. Hitchcock \& M. Verheij, (eds.)

Berlioz, D.; Nef, F. (eds.) (1999). "L'actualité de Leibniz: Les deux Labyrinthes", Studia Leibnitiana Supplementa 34.

Bermejo, J. C.; Piedras, P. A. (1999). Genealogía de la historia. Madrid: Akal.

Brauer, D. Et AL. (2013). New Perspectives in Global History. Hannover: Wehrhahn Verlag.

Danto, A. (1965). Analytical Philosophy of History. London \& New York: Cambrigde University Press.

Duso, G. (2006). La rappresentanza politica: genesi e crisi del concetto. Milan: Franco Angeli.

Flint, R. (1874). The philosophy of history in France and Germany. Edinburgh and London: William Blackwood and Sons.

Hitchсоск, D.; Verheij, M. (eds.) (2006). Arguing on the Toulmin model New Essays in Argument Analys and Evaluation. Dordrecht: Springer.

Israel, J. (2001). Radical Enlightenment: Philosophy and the Making of Modernity, 1650-1750. Oxford University Press.

Kant, I. (2006). Ideas para una historia universal en clave cosmopolita y otros escritos de Filosofía de la Historia, Roberto Rodríguez Aramayo y Concha Roldán (trads.). Madrid: Tecnos.

Koselleck, R. (1989). Vergangene Zukunft. Freiburg/München: Suhrkamp.

— (1959). Kritik und Krise. Freiburg/München: Suhrkamp.

Leibniz, G.W. [GP]. Die Philosophischen Schriften von Gottfried Wilhelm Leibniz. Edited by C.I. Gerhardt, 7 vols. Berlin: Weidman,1875-1890 (reimp. Hildesheim, 1960-61). 
- (1903). Opuscules et fragments inédits de Leibniz, L. Couturat (ed.), París (reimp. Hildesheim, 1966).

- [Grua]. Textes inédites d'après la Bibliothèque Provinciale de Hanovre, G. Grua (ed.), 2 vols. Paris: Presse Universitaires de France, 1948 (reimp. PUF 1998).

- (1962). Nouveaux Essais sur l'entendement humaine, A. Robinet y H. Schepers (eds.), Sämtliche Schriften, Reihe VI, Vol. VI. Berlin : Akademie Verlag.

- (1982). Escritos filosóficos, E. de Olaso, (ed.), Buenos Aires: Charcas.

- (2012). Obras filosóficas y científicas (OFC). Granada: Comares.

Meinecke, F. (1946). Die Entstehung des Historismus. München: Leibniz Verlag.

Racionero, Q.; Dascal, M. (1992). "La racionalización de la política”, Revista latinoamericana de filosofia XVIII, no 1, p. 96.

- (2006). G. W. Leibniz. The Art of Controversies. The Netherlands: Springer.

RoldÁN, C. (1989). "Das Vollkommenheitsprinzip bei Leibniz als Grund der Kontingenz", en Studia Leibnitiana XXI/2, pp. 188-195.

- (1990). "La salida leibniziana del laberinto de la libertad", G.W. Leibniz. Escritos en torno a la libertad, el azar y el destino. Madrid: Tecnos, pp. IX-LII.

— (1992). "El principio de perfección y la idea de progreso moral en Leibniz", en $I l$ cannocchiale. Rivista di Studi filosofici, pp. 25-44.

- (1995). "Las raíces del multiculturalismo en la crítica leibniziana al proyecto de paz perpetua", en Saber y conciencia, J.A. Nicolás y J. Arana (eds). Granada: Comares, pp. 369-394.

- (1997). "Theoria cum praxi: la vuelta a la complejidad (Apuntes para una filosofía práctica desde el perspectivismo leibniziano)”, Isegoria 17, pp. 85-105.

- (2005). Entre Casandra y Clio. Una historia de la filosofia de la historia. Madrid: Akal.

- (2009). "Ilustración y semántica histórica: el protagonismo de Leibniz", en Teorías $y$ prácticas de la Historia Conceptual, Faustino Oncina (ed.). Madrid: CSIC-Plaza y Valdés.

- (2015). Leibniz. En el mejor de los mundos posibles. Barcelona: Batiscafo.

Roldán, C.; Moro, O. (eds.) (2009). Aproximaciones a la contingencia. Madrid: Catarata.

Oncina, F. (2009). Teorias y prácticas de la Historia Conceptual, Faustino Oncina (ed.). Madrid: CSIC-Plaza y Valdés.

Thiebaut, C.(1988). Cabe Aristóteles. Madrid: Visor, Madrid. 
Villacañas, J.L. (2009). "Acerca del uso apocalíptico de la E. Media", en Teorías y prácticas de la Historia Conceptual, Faustino Oncina (ed.). Madrid: CSIC-Plaza y Valdés.

Villaverde, Ma J.; Laursen, Ch. (eds.) (2011). Forjadores de la tolerancia. Madrid: Tecnos.

- (eds.) (2012). Paradoxes of Religious Toleration in Early Modern Political Thought. New York, Toronto, Plymouth, UK: Lexinton Books.

Wundt, M. (1939). Die deutsche Schulmetaphysik des 17. Jahrhunderts. Tübingen: Mohr.

— (1945). Die deutsche Schulphilosophie im Zeitalter der Aufklärung, Hildesheim: Olms,

Recibido: 30/09/2016

Aceptado: 15/10/2016

Este trabajo se encuentra bajo una licencia de Creative Commons Reconocimiento-NoComercial-SinObraDerivada 4.0 Internacional

\section{c) (1) 9

